\title{
A retórica do capítulo IX do tratado Da Interpretação
}

\author{
Luisa Buarque
}

This paper analyses the argumentative strategy of the ninth chapter of the treatise $D e$ Interpretatione in the light of Aristotle's Rhetoric. The subject of the 'future events' developed in chapter IX brings up themes that are proper not only to philosophical thought, but also to political practice, forensic rhetoric, deliberative rhetoric and even tragic poetry. In this paper, it is argued that Aristotle uses the dialectical method and certain rhetorical techniques to touch the various discussions related to the subject addressed. He erects a hypothetical adversary and a thesis to refute, condensing some positions that were probably scattered in the most diverse textual and oratory sources of his time. Moreover, he builds the thesis of his hypothetical opponent from premises established in previous chapters of his own treatise. With this, he can simulate the defense of his opponent's thesis before demolishing it. Thus, according to the hypothesis defended here, the philosopher does not in fact commit himself to the arguments presented between $18 \mathrm{a} 35$ and $18 \mathrm{~b} 25$, but only simulates the defense of the reasoning which he will soon refute. In addition, it is also concluded that chapter IX is part of the argumentative chain of the treatise, having as a peculiar characteristic, not the theme or nature of the arguments exposed, but the rhetorical method it employs.

\section{Introdução}

No famoso capítulo IX do tratado Da Interpretação, Aristóteles se pergunta a respeito da influência do ingrediente 'tempo' sobre o valor de verdade de uma sentença. Se as conclusões dos capítulos anteriores acerca da veracidade ou falsidade das proposições apofânticas ${ }^{1}$, e especialmente dos pares de proposições contraditórias, eram válidas em certas condições, existe pelo menos um caso que gera problemas para as regras vigentes até então, a saber, o caso dos “indivíduos que vão ser" (18a33)², ou

\footnotetext{
${ }^{1}$ Até então, ficamos sabendo, grosso modo, que existem regras para pares de proposições contraditórias (RPC). Estando estabelecido um princípio, conhecido como o Princípio da Bivalência (PB), que reza que toda afirmação ou negação apofântica (ou declarativa) é verdadeira ou falsa, a RPC afirmará que, dado um determinado par de sentenças contraditórias, se uma é verdadeira a outra é falsa, com a exceção dos casos universais tomados não universalmente. Neste último caso, a RPC não necessariamente se sustenta.
}

${ }^{2}$ Traduções do Da Interpretação de Ricardo Santos, 2014. 
ainda, o caso dos eventos singulares que ocorrerão no futuro, se forem de tipo contingente.

A estratégia que Aristóteles traça nesse capítulo de seu tratado tem momentos dúbios e foi muito discutida ao longo da história. Parece haver consenso em torno do fato mais geral de que ele deseja refutar a posição dos fatalistas ${ }^{3}$ e defender a contingência e a indeterminação do futuro. $O$ consenso, no entanto, termina aí, uma vez que a saída proposta pelo filósofo permanece sendo um ponto disputado, e isso desde a Antiguidade ${ }^{4}$. A controvérsia, além disso, é potencialmente interminável, pois, ao expor a posição que pretende refutar, o filósofo parece utilizar suas próprias premissas e conclusões, de modo que o leitor não tem como saber com certeza quais afirmações estão sendo de fato endossadas pelo filósofo e quais estão sendo rejeitadas. Em resumo, sabemos qual é a ontologia e qual é a física aristotélica que subjazem ao capítulo, porém não sabemos qual é a teoria lógico-linguística que melhor corresponde a elas.

A análise que eu gostaria de propor aqui se dirige mais para a estratégia formal do capítulo IX do Da Interpretação do que propriamente para o conteúdo da solução proposta por Aristóteles para os problemas ali surgidos. Assim, não será meu intuito defender uma hipótese sobre os detalhes da sua posição, tampouco sobre a forma lógica dos argumentos que ao fim poderão ser atribuídos ao filósofo. Eu gostaria apenas de sustentar uma determinada leitura de sua tática argumentativa, que proponho chamar de retórica - segundo a própria concepção aristotélica de "técnica retórica" exposta em seu tratado dedicado ao assunto ${ }^{5}$.

\footnotetext{
${ }^{3}$ Uma designação usada aqui de modo propositalmente genérico, referindo-se às concepções de que o futuro está de algum modo pré-determinado, ou de que tudo o que acontece, acontece por necessidade - excluindo, portanto, a casualidade, ou aquilo que ocorre, no linguajar aristotélico, apó tukhés.

${ }^{4}$ Cf. Santos, 2014, p. 10: "Na última parte do capítulo (a partir de 19a23), Aristóteles diz-nos onde é que o argumento determinista erra. Até hoje, os leitores deste texto não conseguiram chegar a acordo sobre qual é a solução proposta por Aristóteles." Muito resumidamente, boa parte da controvérsia gira em torno de saber se Aristóteles teria aberto uma exceção para o Princípio da Bivalência (PB) nesse capítulo. E, se sim, qual seria a sua argumentação exata para fazê-lo. Cf.: Fine, 1984, pp. 23-47; Frede, 1985, pp. 31-87. Uma outra opção interpretativa é a de Whitaker (Whitaker, 1996), para quem Aristóteles não abre uma exceção para o PB, e sim para a RPC, ou seja, a regra dos pares de contraditórias.

${ }^{5}$ Após a redação deste texto, tomei conhecimento do artigo de Hintikka (1964). Segundo ele: "What is the typical strategy of an Aristotelian argument? Often the difficulty of understanding his remarks is not due to their complexity, but to the fact that he is proceeding dialectically. He presents arguments and well-founded opinions first for one side and then for the other. The clash between the two gives rise to an aporia to be solved. Aristotle's own position is normally achieved by a conceptual analysis of the arguments which gave rise to the aporia." (1964, p.
} 
Estou consciente de que, contra a ideia de que Aristóteles se vale nesse capítulo de uma tática retórica em sentido estrito, poder-se-ia alegar que o tratado $D a$ Interpretação apresenta um discurso científico, do qual é próprio o ensino e não a persuasão (cf. Retórica, 1355a26). Nesse sentido, tratar-se-ia de um contexto que de antemão excluiria a 'retórica'. Todavia, segundo o próprio Aristóteles, todo conhecimento precisa ensinar e persuadir em sua área própria (Retórica, 1355b28), e, além disso, os discursos persuasivos são úteis "quando se fala contra um adversário, ou contra uma tese proposta" (Retórica, 1391b12). Nesse sentido, é possível que a própria natureza do assunto abordado no capítulo IX do tratado exija de Aristóteles mais do que o discurso científico, uma vez que existe uma divergência não apenas filosoficamente importante, mas também culturalmente enraizada - talvez mesmo popular - a respeito do problema dos eventos futuros. O que faz com que, em última instância, Aristóteles deseje persuadir o seu leitor/aluno de que é ele quem está certo e não o fatalista, precisando trazer à baila propriamente uma "prova por persuasão", isto é, essa "espécie de demonstração" (Retórica, 1359a) ${ }^{6}$, contendo entimemas demonstrativos e refutativos ${ }^{7}$.

Sendo assim, ao debruçar-se sobre o assunto dos eventos que ocorrerão no futuro, Aristóteles abre uma brecha em seu tratado, como pretendo sustentar, através da qual é possível entrever situações e questionamentos que fazem parte não apenas da discussão filosófica, mas também da experiência comum de seus interlocutores. Ele

468) Concordo plenamente com estas últimas afirmações. Entretanto, o meu procedimento aqui difere completamente do procedimento do autor. Para Hintikka, "appreciating this structure does not yet throw much light on his solution" (1964, p. 469), de modo que ele não se demorará sobre a estratégia de Aristóteles nem desenvolverá o caráter dialético do argumento. Ele preferirá analisar o seu desenlace, isto é, o trecho onde se encontra a solução do filósofo, que, para ele, procura manter as partes saudáveis da argumentação de seus opositores. Por fim, discordo de algumas das conclusões do autor, como ficará claro à frente.

\footnotetext{
${ }^{6}$ Segundo o Estagirita nesse trecho da Retórica: "Ora, sendo evidente que o método técnico é o que se refere às provas por persuasão e que a prova por persuasão é uma espécie de demonstração (pois somos persuadidos sobretudo quando entendemos que algo está demonstrado), que a demonstração retórica é o entimema e que este é, geralmente falando, a mais decisiva de todas as provas por persuasão; que, enfim, o entimema é uma espécie de silogismo, e que é do silogismo em todas as suas variantes que se ocupa a dialéctica..." (Retórica, 1355a4-11). Todas as traduções da Retórica por Manuel Alexandre Júnior, Paulo Farmhouse Alberto e Abel do Nascimento Pena, 2005.

${ }^{7}$ Cf.: "Há duas espécies de entimemas: os demonstrativos de algo que é ou não é, e os refutativos; a diferença é igual à que existe na dialéctica entre refutação e silogismo. $\mathrm{O}$ entimema demonstrativo é aquele em que a conclusão se obtém a partir de premissas com as quais se está de acordo; o refutativo conduz a conclusões que o adversário não aceita." (Retórica, 1396b23-27).
} 
tangencia questões extensamente abordadas por autores de várias épocas, estilos e estirpes, tais como os temas da deliberação, da decisão e da responsabilidade. Temas que são, aliás, tão mais familiares aos gregos quanto mais próprios à prática política, à retórica forense, à retórica deliberativa ${ }^{8}$ e até à poesia trágica. Por mais que a questão do descrédito ao oráculo, por exemplo, estivesse em voga já no século $\mathrm{V}$ e no começo do $\mathrm{IV}^{9}$, portanto muito antes de Aristóteles escrever seu tratado, sabemos também que a alternativa do fatalismo sempre abriu as suas asas por sobre o imaginário popular e filosófico grego antigo (e não meramente grego nem meramente antigo, pois o mesmo tipo de concepção pode ser verificado em várias outras tradições culturais e filosóficas, em qualquer época da história), tendo sido fortemente defendida por algumas escolas filosóficas. Parece-me possível, portanto, que neste caso específico o Estagirita tenha recorrido a uma estratégia persuasória, onde se fez necessário apelar para certas endoxa e, se não propriamente fazer um recenseamento das posições que podem ser tidas como fatalistas, ao menos construir com elas um oponente único em forma de raciocínio. Afinal, para Aristóteles, sem a retórica a verdade pode ser derrotada; além disso, pertence a ela debater os dois lados de uma questão:

É preciso ser capaz de argumentar persuasivamente sobre coisas contrárias, como também acontece nos silogismos; não para fazer uma e outra coisa - pois não se deve persuadir do que é imoral - mas para que nos não escape o real estado da questão e para que, sempre que alguém argumentar contra a justiça, nós próprios estejamos habilitados a refutar seus argumentos. Ora, nenhuma das outras artes obtém conclusões sobre contrários por meio de silogismos a não ser a dialética e a retórica, pois ambas se ocupam igualmente dos contrários. Não porque os factos de que se ocupam tenham igual valor, mas porque os verdadeiros e melhores são pela sua natureza sempre mais aptos para os silogismos e mais persuasivos. (Retórica,1355a29-38)

Assim, se a minha proposta de leitura se sustentar, no caso do capítulo IX do $D a$ Interpretação Aristóteles ter-se-ia ocupado, não da justiça, mas sim da verdade (uma verdade que, aliás, não deixa de exercer sua influência sobre a justiça), abordando os pontos de vista e princípios contrários, assim como um dialético ou um retórico. Ele teria utilizado o terceiro método técnico de persuasão - os lógoi, argumentos (Retórica,

\footnotetext{
${ }^{8}$ Aliás, quanto a isso é útil lembrar que, segundo Aristóteles, é próprio de um dos três gêneros de retórica, a saber, da retórica deliberativa, pronunciar-se sobre certas coisas futuras (Retórica, 1358b4-8).

${ }^{9}$ Pensemos em Jocasta tentando persuadir Édipo de que ele não devia temer as previsões do oráculo (Édipo Rei.); também em Aristófanes botando em cena vendedores de oráculos (Aves) e zombando das previsões do futuro político (Cavaleiros); por fim, pensemos em Tucídides comentando a influência dos oráculos sobre a guerra (História da Guerra do Peloponeso).
} 
1356a4) -, apropriando-se dos contrários para ao fim persuadir do que é verdadeiro e, a seu ver, ética e politicamente preferível.

Para expor resumidamente aquilo que defenderei pormenorizadamente a seguir, penso que a estrutura do capítulo IX pode ser reconstituída, grosso modo, da seguinte maneira: logo depois das primeiras linhas, em que apresenta o problema a ser abordado (DI, 18a28-34), Aristóteles passa abruptamente para a execução da primeira parte de sua estratégia retórica, que consiste em um fingimento. Ele simula adotar um conjunto de argumentações, que expõe a fim de passear provisoriamente pelo raciocínio daquele que deseja contraditar (DI, 18a35-b25), para depois desmontá-lo e revelar em que sentido esse raciocínio desmorona (a partir de DI, 18b26). Ao longo dessa simulação, o filósofo parece empregar uma boa parcela das premissas e conclusões que haviam sido manejadas e expostas nos capítulos anteriores do tratado, porém em seguida ele as refutará, mostrando que esse emprego não fora propriamente saudável no contexto do assunto abordado pelo nono capítulo, e revelando finalmente a sua própria posição. Assim, é possível afirmar que a totalidade de sua estratégia se constitui de uma breve apresentação do problema, de uma parte simulativa ${ }^{10}$, de uma parte refutativa e, por fim, de um posicionamento (que eu não chegarei a analisar em detalhes).

Ainda que esta tentativa de estruturar a estratégia formal aristotélica do capítulo IX dividindo-o em partes não nos traga esclarecimentos a respeito do conteúdo do posicionamento final do filósofo, penso que ela é importante porque nos permite ler o conjunto de observações que vai de $18 \mathrm{a} 35$ a 18b25 como uma verdadeira simulação, isto é, como a exposição de um conjunto de raciocínios que, no entender de Aristóteles, não se sustentariam no contexto em questão ou, no mínimo, não estariam sendo aplicados ao referido problema da maneira correta ${ }^{11}$. Logo, se a leitura retórica do

\footnotetext{
${ }^{10}$ Ackrill faz uma observação a respeito dessa parte que dá algum apoio à ideia de simulação: "Here and in what follows he [Aristotle] puts himself in the place of the determinist..." (Ackrill, 2007, p. 136).

${ }^{11}$ Não posso concordar, portanto, com a divisão proposta por Ackrill (Ackrill, 2007, p. 135), para quem o capítulo tem como parte 1 a exposição inicial e como parte 2 os passos 18a3519a6. Penso que, com essa divisão, misturam-se dois momentos distintos, a saber, o momento da exposição da posição do adversário (que chamo de parte simulativa) e o momento de refutação e desmoronamento da simulação. É verdade que entre $18 \mathrm{~b} 25$ e $19 \mathrm{a} 6$ Aristóteles chega a afirmar uma última vez as conclusões dos fatalistas (19a2-6), mas essa última afirmação, a meu ver, tem claramente o papel de resumir em poucas palavras as tais conclusões absurdas a que ele acabara de se referir e cuja refutação já começara a realizar. Logo, trata-se antes de um último resumo do que fora exposto, e não de uma última afirmação em sentido estrito. Aliás, os tradutores franceses M. Crubellier, C. Dalimier e P. Pellegrin entendem a sintaxe desse trecho de um modo muito favorável à minha interpretação: "Pour cette phrase et la suivante, nous
} 
capítulo IX fizer sentido, seremos obrigados a concluir que o filósofo não pode se comprometer de fato com os argumentos expostos entre $18 \mathrm{a} 35$ e $18 \mathrm{~b} 25$, por mais parecidos que alguns deles sejam com afirmações que o próprio Aristóteles havia defendido anteriormente. Levando isso em consideração, é possível que algumas das interpretações da solução do filósofo para o problema dos eventos futuros contingentes se sustentem melhor. Porém, para que isso possa ser aceito, será preciso mostrar em que sentido o filósofo parece manejar as suas próprias premissas e conclusões nessa parte simulativa do texto, sem o fazer propriamente. É o que procurarei realizar, oferecendo uma análise mais detalhada do passo a passo da parte inicial do capítulo e procurando defender a leitura exposta até aqui.

\section{Uma Simulação}

Se de fato a primeira parte da tática retórica do capítulo IX do Da Interpretação consiste em uma simulação de adoção da posição do fatalista, então faz sentido que nesse trecho Aristóteles lance mão de alguns dos termos, noções e premissas surgidos nos primeiros capítulos do tratado DI de modo proposital; por um lado, ele nos convencerá, ainda que temporária e provisoriamente, de uma tal simulação, e, por outro lado, nos mostrará de que modo o fatalista erra na utilização de premissas que poderiam ser saudáveis, caso fossem bem manipuladas. Examinando-se o texto de perto, nota-se que toda a argumentação que compõe essa parte simulativa repousa inteiramente sobre duas observações, que serão feitas em forma de afirmação peremptória logo no começo do capítulo, após a breve apresentação do problema a ser enfrentado. São essas duas observações que sustentarão todo o raciocínio do fatalista, tal como reconstituído e aparentemente adotado por Aristóteles.

A primeira observação tem a seguinte formulação: a) "Pois, se toda afirmação ou negação é verdadeira ou falsa, também é necessário que tudo pertença ou não pertença”.

divergeons de certains (Tricot, Cooke, Zanatta) qui comprennent les imparfaits comme se référant au passé. Nous comprenons la phrase comme un système hypothétique irréel, la particule conditionelle ' $a n$ ' étant régulièrement omise avec l'expression verbale d'obligation 'anagkáion en' ou l'expression impersonelle 'alethés en' (toutes deux à l'imparfait)." (Crubellier, Dalimier, Pellegrin, 2007, nota 8, p. 341). Crivelli (2044, p.198) faz uma divisão geral do capítulo idêntica à minha em termos quantitativos, porém sem dar os mesmos nomes, evidentemente, pois o seu objetivo é refutar o chamado Princípio de Bivalência. Assim, ele não considera propriamente como simulações os argumentos que vão de 18a35-b25. 
$D I, 18 \mathrm{a} 35)^{12}$. Segue-se a ela uma conclusão clara: "Pois, se uma pessoa disser que uma certa coisa irá ser e outra pessoa negar isso mesmo, é evidente que uma delas está a dizer a verdade - se toda afirmação é verdadeira ou falsa; pois não poderão pertencer ambas ao mesmo tempo em tais circunstâncias." (DI, 18a36-40). Em aparência, a lógica de Aristóteles aqui é límpida. Ele parece estar dizendo algo como: se, em uma espécie de aposta, uma pessoa afirmar que um evento ocorrerá e outra pessoa afirmar que o mesmo evento não ocorrerá, é evidente que apenas uma delas estará com a razão e ganhará o prêmio. Essa aparente obviedade, naturalmente, tende a ganhar a adesão imediata do leitor. Não obstante, a limpidez de tal lógica parece-me ser enganosa. Vejamos como.

O que o filósofo está afirmando é que a verdade ou falsidade das sentenças dos dois apostadores está garantida pelo princípio da bivalência anteriormente suposto, ou seja: se toda afirmação ou negação declarativa é verdadeira ou falsa - pois "é possível declarar o que pertence como não pertencente, o que não pertence como pertencente, o que pertence como pertencente e o que não pertence como não pertencente. E do mesmo modo para os tempos fora do presente", DI 17a30 -, então isso deve valer também para a aposta em questão. Com isso, o princípio da bivalência sustenta o restante do argumento, desempenhando o papel de premissa. É como se, após ter sido estabelecido $^{13}$ e empregado nos capítulos anteriores do tratado, Aristóteles o utilizasse aqui como premissa para suas próximas conclusões. Porém, o que ele fará a seguir, para a decepção do leitor, é concluir de volta aquilo que sustentou a própria suposição do princípio da bivalência nas páginas anteriores. Explico-me: se o fato de que algo pertence (por exemplo, é preto) faz verdadeiro declarar que é preto, e correspondentemente o fato de que não pertence (por exemplo, não é preto), faz verdadeiro declarar que não é preto, a conclusão de Aristóteles tem, no trecho examinado, um formato invertido: "Pois, se é verdade dizer que é branco ou não é branco, então é necessário que seja branco ou não seja branco.” (DI, 18b1). Em suma, é como se a conclusão virasse premissa de sua própria premissa, pois a forma condizente

\footnotetext{
${ }^{12}$ Como lembra o tradutor, pertencer é a expressão utilizada pelo filósofo para denotar a predicação.

${ }^{13}$ Digo 'estabelecido', porque penso que ele não seja propriamente deduzido em lugar algum, uma vez que Aristóteles já parte da exclusão das sentenças não declarativas. De todo modo, estabelece-se que as sentenças declarativas são declarativas, porque certas coisas pertencem e certas coisas não pertencem. Ir além disso sairia do escopo do tratado, mas esse fator torna-se relevante justamente no capítulo IX.
} 
com 17a30 supracitado seria antes algo como: se é [necessário que seja] branco ou não [seja] branco, então é verdade dizer que é branco ou não é branco. Assim, o formato invertido apresentado como uma primeira conclusão na parte simulativa só poderia ser válido caso o formato não invertido estivesse garantido. Parece-me claro, portanto, que não se trata apenas de passar da verdade para a necessidade, como nota Whitaker, mas, sobretudo, de passar da verdade lógica para a verdade ontológica, isto é, para o ser (ou pertencer) extralinguístico. Em suma, há uma inversão sendo levada a cabo neste momento, e o que ela nos induz a crer é que uma constatação de ordem lógicolinguística leva a um acontecimento na realidade, enquanto que o contrário é que seria defensável. Assim, ainda que a lógica manejada seja saudável, ela é mal aplicada ao caso analisado.

Como veremos adiante, a inversão lógica será desfeita por Aristóteles com toda propriedade e clareza em 18b37-40, e não me parece nem que ele tenha cometido mera falácia ${ }^{14}$, nem que tenha proferido um argumento inocente ${ }^{15}$, nem que tenha sido temporariamente convencido de algo cujo fracasso ${ }^{16}$ ele depois admite. Parece-me, simplesmente, um passo inteiramente proposital, uma clara manobra tática que deve passar despercebida ao leitor para que a estratégia retórica do capítulo como um todo funcione ${ }^{17}$. A meu ver, a operação é feita de modo rápido e pouco explicado, justamente para que sua solidez pareça assegurada pelo que fora exposto anteriormente, e para que a sua inversão permaneça escamoteada pela aparente limpidez do argumento apressado.

Se a estratégia funcionar e essa inversão lógica passar despercebida, chegaremos à segunda observação a sustentar o raciocínio do fatalista, que se junta com a conclusão da primeira observação. Ela é formulada assim: b) “...se é branco ou não é branco, então era verdade dizê-lo ou negá-lo.” (DI, 18b3). Aqui, como se nota, ele acrescenta à conclusão da formulação a) uma outra formulação b) dotada de um elemento temporal: "se é branco ou não é branco, então era verdade dizê-lo ou negá-lo". A operação, como de costume, parece logicamente límpida: trata-se de concluir, após a aposta firmada e após a verificação do vencedor, qual teria sido a melhor opção para o apostador que

\footnotetext{
${ }^{14}$ Ackrill, p. 133.

${ }^{15}$ Whitaker, p. 116.

${ }^{16}$ Ackrill, p. 137 (o termo utilizado é "flaw").

${ }^{17}$ Procurarei mostrar logo adiante como ele mesmo denunciará essa inversão, de modo que me parece absolutamente artificial defender que o filósofo tenha afirmado isto aqui com sinceridade, para apenas alguns parágrafos depois desdizer o que acabara de concluir.
} 
perdeu a aposta. Ou seja, o perdedor lamenta-se por não ter afirmado o contrário do que afirmou, pois, se o tivesse feito, teria sido premiado. Mais uma vez, porém, o que se verifica é uma inversão, só que desta vez de ordem temporal: considera-se no presente que teria sido melhor, no passado, escolher ou afirmar tal opção acerca do futuro. Mas isso, evidentemente, só pode acontecer porque hoje, no presente, tendo esse futuro se concretizado, já podemos retroativamente examinar se, digamos, o cartomante acertou ou não acertou a sua previsão; da mesma forma, já podemos premiar o apostador que afinal se mostrou o vencedor de uma determinada aposta, assim como o perdedor já pode se arrepender de sua opção. Essa segunda inversão também será enfrentada com clareza e contundência mais adiante (em parte, na mesma passagem 18b37-40, em parte na passagem 19a20-28), assim como a primeira. Porém, também como a primeira, ela por ora precisa passar despercebida.

Assim, o que temos na soma das formulações a) e b) é a associação de duas inversões: a inversão lógica da observação a), em que se passa injustificadamente da ordem lógico-linguística para a ordem ontológica; e a inversão temporal da observação b), em que uma constatação acerca da realidade feita no presente é lançada retroativamente para um passado linguístico. Além disso, e como afirmado antes, são essas duas inversões que, se devidamente aceitas pelo leitor, permitirão ao Estagirita dar um desenvolvimento mais extenso ao raciocínio do fatalista; de modo que, a partir do momento em que são formuladas, as observações a) e b) serão fartamente exploradas para, em seguida, serem desmanteladas a fim de que a posição aristotélica venha à tona de modo mais potente. Desta forma, o desenvolvimento que vai de $18 \mathrm{~b} 3$ a 18b26 de algum modo limita-se a repetir ou reformular as observações a) e b), como se essa repetição pudesse de fato provar o conjunto do raciocínio e da tese que ambas fundamentam.

\section{O Desenvolvimento da Simulação}

Se nos fixarmos na observação a), veremos que ela é repetida uma primeira vez logo depois da formulação da observação b): "E, se não pertence, é falso; e, se é falso, então não pertence". (DI, 18b3). Essa segunda maneira de formular a observação a) é mais palatável, pois agora é-nos fornecida primeiro a ordem que vai da ontologia para a lógica, e em seguida a ordem inversa; de modo que ditas assim, uma seguida da outra, elas formam um conjunto logicamente seguro, pois indicam que a mesma coisa que não 
pertence e que torna uma determinada frase falsa nos permite transitar de volta da frase falsa para o não-pertencimento. E de fato nos permite, porém não se percebe como esse trânsito seria aplicável ao caso em que nenhum pertencimento sustenta a veracidade ou a falsidade da sentença. Ou seja, a segunda parte de $18 \mathrm{~b} 3$, que corresponde à observação a), não se pode manter de pé sem a primeira parte da frase, que exibe a ordem da ontologia para a lógica. Mas é justamente essa manobra que será feita, pois Aristóteles manterá ativa apenas a parte lógica da afirmação - "Portanto, é necessário que a afirmação ou a negação seja verdadeira" (DI, 18b4) -, e em seguida passará a formular a tese fatalista a partir de tal constatação - "Por consequência, nada é ou vem a ser, ou será ou não será, por acaso ou de maneira casual, mas sim tudo por necessidade e não de maneira casual, uma vez que ou o que diz ou o que nega está a falar verdade”. (DI, 18b6-8). Com isso, percebemos que o raciocínio do fatalista não é propriamente falso em seus pontos de partida, mas sim desatento ou descuidado na aplicação e no manejo de suas premissas.

Uma outra retomada da observação a) será encontrada mais adiante: "Além disso, se é verdade dizer que algo é branco e grande, ambas as coisas têm de lhe pertencer." (DI, 18b21). Aqui temos novamente uma formulação mais palatável da observação a), uma vez que ela é dita na forma de uma condicional. Porém, uma vez que essa condicional se segue aos trechos onde fora estabelecido ser necessário que a afirmação ou a negação seja verdadeira, então essa condicional passa a ser concludente e, transferida para o tempo futuro, passa a determinar a necessidade de certas coisas pertencerem ou não pertencerem. Assim, as duas reformulações da observação a) permitem ao filósofo tirar conclusões fatalistas, tais como: "nada é por acaso" (18b6) e "não é de maneira casual" (18b24).

A observação b), por sua vez, é reafirmada entre as duas ocorrências mencionadas acima: "Além disso, se é branco agora, era verdade dizer antes que iria ser branco." (DI, 18b10) Aqui, a formulação varia pouco, mas de forma decisiva. Se da primeira vez lemos que "era verdade dizê-lo ou negá-lo", agora lemos que "era verdade dizer antes (próteron) que iria ser branco". Como se nota, a presença do próteron ilumina e reforça a anterioridade que está em jogo nessa inversão temporal. Conforme já fora afirmado: considerada do presente, uma determinada aposta teria sido a melhor no passado, pois só uma coisa viria a ser verdadeira, só uma opção viria a realizar-se. Daí, porém, segue-se rapidamente a conclusão desejada pelo fatalista: "Portanto, de qualquer coisa que veio a ser, sempre foi verdade dizer que seria. Mas, se foi sempre verdade 
dizer que é, ou que será, então isso não pode não ser, ou não ir ser" (DI, 18b11-13). Chega-se uma segunda vez à mesma conclusão, agora utilizando a observação b) no lugar da a). E é justamente o reforço dessa inversão temporal que levará o filósofo a inserir em seu texto os termos modais, que agora se tornam centrais para melhor delinear a posição do fatalista que ele está simulando, pois se algo não pode não ocorrer, então é necessário que ocorra e impossível que não ocorra.

Após as retomadas das duas observações e a exposição da mesma conclusão que se pode retirar de ambas, temos uma espécie de virada interior à parte simulativa da estratégia retórica aristotélica. O que ocorre é que se passa ao exame de uma segunda alternativa até agora inexplorada, a saber, a de que o par de sentenças contraditórias a respeito de um evento contingente no futuro seja formado por duas proposições falsas. É justamente nesse trecho que surgirá o famoso exemplo da batalha naval. Esse momento do raciocínio é importante porque, aparentemente, uma nova solução poderia ser encontrada na negação da regra dos pares de contraditórias, segundo a qual uma sentença contraditória é sempre verdadeira e a outra é sempre falsa, com a única exceção do caso das universais ditas não universalmente. Se a conclusão acerca da necessidade do futuro derivou dessa regra - pois se uma das duas sentenças era verdadeira, então a situação à qual ela se referia também já estava destinada a acontecer -, talvez seja o caso de a solução procurada ser simplesmente a falsidade de ambas e, portanto, a negação da realidade a que se referem. Todavia, o filósofo conclui rapidamente que nesse caso tanto seria falso que haverá quanto seria falso que não haverá uma batalha naval amanhã; isto é, nada ocorreria amanhã. Como nota Whitaker (1996, p. 118), o que Aristóteles pretende mostrar é que, longe de solucionar o problema, o que essa saída faz é adicionar um outro problema ao nosso quadro, porque agora teremos que concluir que o futuro é impossível. Ou seja, segundo a leitura retórica que estou propondo, o que temos nesse momento do texto é que, implicitamente, o leitor começa a concluir que, enquanto aquelas duas observações a) e b) não forem refutadas, e enquanto não for restabelecida a eficácia lógica da aplicação das premissas ao presente caso, simplesmente não haverá solução possível ${ }^{18}$.

\footnotetext{
${ }^{18}$ Para mim, portanto, mesmo sem saber se é o PB ou a RCP, ou nenhum deles, que é negado, nota-se ser necessário de algum modo ou até certo ponto desconstruir as duas observações que foram propositalmente formuladas, ou seja, retoricamente formuladas com vistas a forçar ao máximo o argumento de seu opositor, para depois destruí-lo mais firmemente.
} 


\section{Um Interlúdio}

Em 18b26, lemos finalmente uma declaração que não poderia ser mais explícita: "Estes, e outros do mesmo tipo, são os absurdos que resultam..." (DI, 18b26). Pareceme que esta visível quebra na continuidade do raciocínio não tem outra função, a não ser a de nos acordar para a manobra que havia sido feita até então. Não à toa, é também nesse trecho - e ainda antes de passar para a segunda parte de sua estratégia retórica, isto é, antes de passar ao momento refutativo do capítulo -, que Aristóteles trará argumentos de ordem ético-política contra as tais conclusões absurdas: "Desse modo, não seria preciso deliberarmos, nem esforçarmo-nos - pensando que, se fizermos isto, será assim, mas se não fizermos, não será”. (DI, 18b31-33) O mundo absurdo é aquele onde, não havendo espaço para o acaso, não há, consequentemente, espaço para a deliberação e o esforço. Neste momento, portanto, o filósofo mobiliza breves, mas incisivas afirmações que, em princípio, pertencem a um âmbito totalmente exterior à hermeneia que delimita o campo de investigação do tratado.

Assim, essa pequena exclamação aristotélica (absurdos!) que marca o fim da primeira parte de sua estratégia retórica representa também o começo de uma espécie de interlúdio, onde será encontrada pela primeira vez a 'brecha' a que me referi na introdução. Trata-se de um pequeno buraco de fechadura na porta do tratado $D a$ Interpretação. Uma fenda por meio da qual o leitor poderá enxergar todo um mundo ético-político pautado pela deliberação, pelas tomadas de decisão, pela insegurança do futuro e pela instabilidade dos eventos humanos que não se podem prever. Dito sucintamente, o que temos aqui é a expressão aristotélica do absurdo de negarmos um princípio deliberativo para as decisões e para os eventos individuais e coletivos. No entender de Aristóteles, é preciso justificar a existência do esforço para que algo se dê e da responsabilidade pelo que se deu, bem como do erro e do acerto (no sentido de que certas coisas são mais desejáveis do que outras). Por breves que sejam as afirmações do filósofo a esse respeito e por estreita que seja essa brecha em seu tratado, ainda assim é lícito ver aqui um Aristóteles que flerta não apenas com princípios ético-políticos, mas também com questões comumente abordadas tanto em textos forenses quanto na poesia trágica do século que o antecedeu. Questões que, curiosamente, não estão presentes no tratado mais técnico que é a Poética, mas das quais não poucas tragédias tratam, a saber, o presságio, a adivinhação, a decisão em nível pessoal e político, a abertura (ou não?) do futuro e a irreversibilidade do passado. Em suma, trata-se de um breve momento em que 
o filósofo aponta para assuntos presentes implícita ou explicitamente em outros de seus tratados, tais como a Política, a Ética a Nicômaco, a Poética e, não por acaso, a própria Retórica ${ }^{19}$. Ademais, é como se Aristóteles não se pudesse furtar ao emprego da técnica retórica justamente lá onde se trata de garantir a sua possibilidade, ou seja, nos campos da prática política e da deliberação em torno dos problemas do melhor e do pior, do justo e do injusto. Isto é, naqueles campos em que a retórica se torna, mais do que útil, absolutamente necessária. Ora, é justamente isso que está em jogo no argumento do fatalista. É precisamente isso que pode ser aniquilado pela possibilidade de o futuro estar previamente determinado.

\section{A refutação e suas consequências}

Eis, por fim, a parte do texto em que serão desmontadas as observações a) e b), que, conforme verificamos, sustentam o edifício classificado pelo filósofo de 'absurdo'. Ao serem desmontadas, claro está que o conjunto edificado por sobre elas desmoronará como um todo. Essa estratégia de adiamento da refutação parece dar especial robustez à tese que o filósofo tem em vista defender. Todavia, ela dependeu de um processo de desafio ao leitor, digamos assim.

Neste momento, e sem mais delongas, o golpe será duro e rápido:

E não faz nenhuma diferença se alguém fez ou não fez as declarações contraditórias. Pois é evidente que é assim que as próprias coisas são, mesmo que não tenha havido uma pessoa a afirmá-lo e outra a negá-lo. Pois não é por causa do afirmar ou negar que será ou não será, nem há mais de dez mil anos, nem em outro tempo qualquer. (DI, 18b37-40).

Ainda que a constatação não seja muito desenvolvida nesse primeiro momento, seu sentido é claro: o ser das coisas independe daquilo que afirmamos sobre elas ("não faz nenhuma diferença se alguém fez a declaração!"). É a linguagem que deve

\footnotetext{
${ }^{19}$ Exemplo: "Nós deliberamos sobre as questões que parecem admitir duas possibilidades de solução, já que ninguém delibera sobre as coisas que não podem ter acontecido, nem vir a acontecer, nem ser de maneira diferente; pois, nesses casos, nada há a fazer." (Retórica, 1357a47). Ou ainda: “...a maior parte dos assuntos sobre que incidem juízos e deliberações pode receber solução diferente, pois deliberamos e reflectimos sobre as acções, todas elas apresentam em comum esta particularidade, e nenhuma delas é, por assim dizer, necessária". (Idem, 1357a23-26). Por fim: "Ora, visto que as coisas impossíveis não podem ter sido feitas no passado, nem se podem fazer no futuro, que apenas as coisas possíveis o podem, que as coisas irreais e irrealizáveis não podem ter sido feitas no passado ou fazer-se no futuro, é necessário que o orador deliberativo, o judicial e o epidíctico tenham premissas sobre o possível e o impossível, se algo aconteceu ou não, e se virá a ter ou não lugar.” (Idem, 1359a11-16).
} 
corresponder às coisas ou aos eventos e não o contrário, de modo que uma afirmação e uma negação não tornam uma coisa nem verdadeira nem falsa, nem necessária nem impossível, mas sim o contrário ${ }^{20}$.

Essa curta porém claríssima correção da inversão lógica da observação a) incidirá, evidentemente, sobre a inversão temporal da observação b) (como se nota já no final da frase supracitada, "nem há mais de dez mil anos, nem em outro tempo qualquer"). Após o evento ocorrido, podemos examinar qual apostador ganhou, mas isso não significa que antes ele já pudesse dispor de uma aposta correta, tampouco que estivesse em condições de proferir uma sentença verdadeira. E isso, não porque ele não tivesse consciência de um futuro pré-determinado mas ainda desconhecido, mas sim porque, no entender de Aristóteles, o futuro não é assim. A ordem que vai da ontologia para a lógica também deve ser respeitada nesse caso. Com isso, temos que, tanto no caso da observação a) quanto no caso da observação b), uma mesma solução é mobilizada. Em ambos os casos, é a ordem correta - do ser das coisas para o ser da linguagem, e não o contrário - bem como a independência da ontologia frente à lógica, que servirá a Aristóteles de argumento refutativo.

Os parágrafos que se seguem nos brindam ainda com algumas repetições e reformulações das ideias aristotélicas trabalhadas até então. A conclusão do fatalista é reiterada no modo de uma condicional (DI, 19a1-6) e é em seguida desafiada ("E se isto for impossível?”, DI, 19a7). Apresenta-se uma segunda vez o argumento da deliberação, e algumas conclusões mais conceituais, e mais contundentes, são retiradas dele:

Pois nós vemos que as coisas futuras têm um princípio tanto na deliberação como na acção e que, em geral, nas coisas que não estão sempre em acto, há a possibilidade [19a10] de ser e de não ser; nelas, ambas as coisas são possíveis: tanto o ser como o não ser e, por conseguinte, tanto o vir a ser como o não vir a ser. E é para nós evidente que muitas coisas são desta maneira. $(D I, 19 \mathrm{a} 8-12)$

Segue-se o famoso exemplo do manto, que pode ser ou não ser cortado, para enfim ser exposta de modo mais didático a ideia de contingência (DI, 19a13-23), entremeada de uma primeira conclusão a respeito da afirmação e da negação de eventos contingentes (19a20). O restante do capítulo trará precisamente a exposição da posição aristotélica, acompanhada de importantes precisões a respeito da diferença entre

\footnotetext{
${ }^{20}$ Assim, não posso concordar com a afirmação de Ackrill, segundo quem Aristóteles "treats laws of logic and laws of nature as on a par" (Ackrill, p. 133). Creio que, ainda que elas possam ser tratadas como paralelas, existe uma clara relação de dependência de uma para com a outra.
} 
contingência e necessidade e de suas consequências lógicas, objeto das longevas controvérsias brevemente resumidas na introdução (e acompanhada também de um último esclarecimento a respeito da questão envolvida na observação a), isto é, do respeito à ordem que vai da ontologia para a lógica ${ }^{21}$ ). E, mesmo que o filósofo reconheça, como afirma Hintikka, que seu "adversário" fatalista utiliza premissas importantes para a instauração de uma lógica saudável e que poderia ter parcialmente razão, ainda assim faz questão de apontar os seus erros na utilização e na aplicação dessa lógica $^{22}$. Nesse sentido, fica ainda mais claro o motivo pelo qual, na parte simulativa, o filósofo parece estar empregando os seus próprios argumentos. Simultaneamente, fica esclarecida a razão da dificuldade do leitor em detectar os momentos em que Aristóteles endossa e aqueles em que ele não endossa o raciocínio fatalista. É que, por um lado, as suas premissas poderiam ser compartilhadas, mas, por outro lado, a manipulação que ele faz delas, ao serem aplicadas ao caso analisado no capítulo IX, é criticada e inteiramente desmontada pelo filósofo: o fatalista utiliza tijolos fortes o suficiente, mas não os encaixa adequadamente, terminando por construir um edifício frágil e absurdo.

Convém notar ainda que, muito perto do final do capítulo - mais precisamente em sua antepenúltima frase, quando se retoma uma última vez a análise dos pares de sentenças contraditórias sobre eventos futuros contingentes, agora com mais clareza em relação ao que significa a contingência -, o leitor afinal percebe que é a própria ideia de aposta que se tornava absurda no mundo do fatalista. Se faz sentido alguém apostar que algo irá ocorrer e outro alguém apostar que o mesmo algo não irá ocorrer, é apenas porque ambos podem sair vencedores, ainda que um tenha mais chance de ganhar do que o outro. Como esclarece Aristóteles: “e mesmo que uma seja mais verdadeira do

\footnotetext{
21 "Por conseguinte, uma vez que os enunciados são verdadeiros da mesma maneira como as próprias coisas são, é claro que, sempre que estas são de modo a admitirem os contrários de maneira casual, o mesmo se aplica necessariamente também à contradição." (DI, 19a33-35).

${ }^{22}$ Por isso, no meu entender faz sentido afirmar, como Hintikka (1964, p. 469), que: "As usual, Aristotle hastens to point out how his solution does justice both to the arguments for the deterministic position and to the arguments against it. As usual, he says in effect that in one sense one party is right and in another sense the other is also right". Porém, não concordo inteiramente com a segunda parte de sua afirmação, a saber: "Be this as it may, it seems to me obvious that Aristotle's criticism of the position of the determinist does not consist in pointing out a fallacy in the latter's argument. It consists in a reinterpretation of the conclusion of the argument." (Idem, p. 477) Creio que em certo sentido ele aponta sim para uma falácia, mas não exatamente em seus pontos de partida, e sim no resultado de sua construção, exatamente como se ele fosse somando pequenos erros até chegar a um ponto muito distante da realidade.
} 
que a outra, isso não implica que tenha de ser verdadeira, ou falsa" (DI, 19a40). A ideia de que algo é "mais verdadeiro" só parece fazer pleno sentido se pensada dentro desse enquadramento, a saber, quando algo ocorre na maioria das vezes, ou ainda, quando tem mais probabilidade de ocorrer do que a outra opção, embora ambas sejam possíveis $^{23}$.

\section{Conclusão}

Para concluir, gostaria apenas de ressaltar que a análise formal do capítulo IX de algum modo justifica a estranheza dele frente ao restante do tratado. Com efeito, se esse for o capítulo onde se pode detectar uma brecha pela qual é possível enxergar todo um mundo ético-político para além da lógica, então é possível que a natureza do tema tenha sido a maior responsável pela estratégia argumentativa levada a cabo nesse contexto. $\mathrm{O}$ que não significa dizer que o capítulo IX é espúrio ou que o DI possa ser lido sem ele; tampouco que ele deva ser considerado um capítulo à parte, tratando de temas externos ao restante da obra. Pelo contrário, penso que, em termos de fundo e de conteúdo, o capítulo se insere muito naturalmente na ordem de exposição e no passo a passo argumentativo do tratado como um todo. Segundo esta análise, portanto, o que lhe fornece um caráter de certa forma distinto não seria nem uma independência temática nem uma autonomia argumentativa, mas apenas a estratégia a que ele recorre para tratar do assunto que é necessário abordar naquele momento, por razões de ordem 'científica'24, que não desobedecem ao desenrolar do fio condutor do texto.

Luisa Buarque

PUC - Rio de Janeiro

\footnotetext{
${ }^{23}$ Cf. Hintikka (1964, p. 485).

${ }^{24}$ No sentido aristotélico do termo.
} 


\section{Referências Bibliográficas}

Aristóteles. Categorias, Da Interpretação. Introdução, tradução e notas de Ricardo Santos. Lisboa: Imprensa Nacional Casa da Moeda, 2014.

Aristóteles. Categories and De Interpretatione. Translated with notes by J. L. Ackrill. Oxofrd: Clarendon Press, 2002.

Aristóteles. Catégories, Sur l'interprétation. Introduction générale à l'Organon par Pierre Pellegrin. Présentations et traductions par Michel Crubellier, Catherine Dalimier et Pierre Pellegrin.Paris : Éditions Flammarion, 2007.

Aristóteles. Da Interpretação. Tradução e comentários José Veríssimo Teixeira da Mata. São Paulo: Editora Unesp, 2013.

Aristóteles. Retórica. Tradução de Manuel Alexandre Júnior, Paulo Farmhouse Alberto e Abel do Nascimento Pena, 2005. Lisboa: Imprensa Nacional Casa da Moeda, 2005.

Crivelli, P. Aristotle on Truth. Cambridge: Cambridge University Press, 2004.

Fine, G. «Truth and Necessity in De Interpretatione 9», in History of Philosophy Quarterly, vol. 1, 1984, pp. 23-47.

Frede, D. «The Sea-Battle Reconsidered: A Defence of the Traditional Interpretation», in Oxford Studies in Ancient Philosophy, 3, 1985, pp. 31-87.

Hintikka. The once and future sea fight: Aristotle's discussion of future contingents in $D e$ Interpretatione IX., in The Philosophical Review, Vol. 73, No. 4 (Oct., 1964), pp. 461-492.

Iacona, A. Future contingent and Aristotle's fantasy, in Crítica, Revista Hispanoamericana de Filosofia. Vol. 39, nº 117 (diciembre 2007): 45-60.

Jones, R. Truth and Contradiction in Aristotle's De Interpretatione 6-9, in Phronesis 55 (2010), p. 26-67.

Whitaker, C. W. A. Aristotle's De Interpretatione. Contradiction and Dialectic. Oxford: Clarendon Press, 1996. 